\title{
Determination of coagulopathy complicating severe preeclampsia and eclampsia with platelet count
}

\author{
Venkata Jayashree, Lakshmi Renukaa*
}

Department of Gynecology and Obstetrics, SVS Medical College, Mahabubnagar, Telangana, India

Received: 21 August 2021

Accepted: 03 September 2021

\author{
*Correspondence: \\ Dr. Lakshmi Renukaa, \\ E-mail: drlakshmirenukaaaa@gmail.com
}

Copyright: (c) the author(s), publisher and licensee Medip Academy. This is an open-access article distributed under the terms of the Creative Commons Attribution Non-Commercial License, which permits unrestricted non-commercial use, distribution, and reproduction in any medium, provided the original work is properly cited.

\begin{abstract}
Background: Preeclampsia is a dangerous complication which occurs potentially in pregnancy and is characterised by high blood pressure. It effects maternal and perinatal health and is complicated by abnormalities of coagulation. The aim of the study was to determine platelet count which predicted coagulopathy in patients with severe preeclampsia and eclampsia.

Methods: Prospective cohort study done in all patients were admitted with diagnosis of severe preeclampsia and eclampsia and admitted for stabilisation. Blood samples were collected from all patients for detecting bleeding, clotting time, electrolytes, urea and creatinine, liver functions tests, full blood count, platelet count, prothrombin time, activated partial thromboplastin time and plasma fibrinogen level in 100 patients in total. Using chi square test, univariate analysis was conducted.

Results: Out of 100 women patients, $70(70 \%)$ patients had severe preeclampsia and $30(30 \%)$ patients had eclampsia out of which 15 patients had thrombocytopenia. The incidence of thrombocytopenia among patients was $16.6 \%$. Biochemical coagulopathy was noted in $7 \%$. Patients with severe preeclampsia had platelet count of $185000 \pm 61289$ per $\mu 1$, PT was $13.52 \pm 1.48 \mathrm{sec}$, APTT was $34.52 \pm 2.49 \mathrm{sec}$ and fibrinogen was $3.16 \pm 0.22 \mathrm{~g} / \mathrm{dl}$. Patients with eclampsia (with thrombocytopenia) had platelet count of $79528 \pm 14897$ per $\mu 1$, PT was $19.25 \pm 5.28 \mathrm{sec}$, APTT was $37.08 \pm 5.33 \mathrm{sec}$ and fibrinogen was $2.67 \pm 0.53 \mathrm{~g} / \mathrm{dl}$. Thrombocytopenia was complicated with eclampsia and it was associated with biochemical coagulopathy which made the condition more severe.

Conclusions: 80000 cells/ $\mu$ l is the thrombocytopenia level which is considered to be critical in severe preeclampsia and eclampsia. This will help to reduce maternal and perinatal mortality and morbidity rates.
\end{abstract}

Keywords: Thrombocytopenia, Prothrombin time, APTT, Fibrinogen

\section{INTRODUCTION}

Haemostasis derangement resulting in either excessive bleeding or clotting which is called impaired clot formation i.e.; coagulopathy. Imbalance between the coagulation and fibrinolytic activities such as preeclampsia, thrombotic system activation results in multiple thrombi development and rapid platelets consumption, prothrombin, fibrinogen and coagulation factors. The most severe complications of preeclampsia and eclampsia is coagulation failure.
The disease is increased significantly by its evolution. A component of the primary disease is developed by coagulopathy and it arises from its complications such as intrauterine fetal death, abruptio placenta or primary postpartum haemorrhage. $15 \%$ of severe preeclampsia cases and it accounts for $15 \%$ of maternal deaths and is affected by coagulopathy. ${ }^{1-5}$ The limited value of preeclampsia and eclampsia population is considered by routine tests which was used to assess decompensated disseminated intravascular coagulopathy. To detect coagulopathy in preeclampsia, more sophisticated tests like determination of antithrombin III, thrombin- 
antithrombin III complex, D-dimer, factor VIII antigen/activity ratio and beta-thromboglobulin are required to be conducted. Routine laboratory tests in detecting DIC are thrombocytopenia, prolonged prothrombin time, prolonged activated partial thromboplastin time and reduction in fibrinogen concentration. Performance of bleeding, clotting time and coagulopathy clinical observation is the cheapest method used in DIC detection. Hence, the basic investigation is platelet count in detecting coagulopathy in severe preeclamptic patients. In preeclampsia and eclampsia, the early coagulation disorder is detected by platelet count which is a rapid, simple and inexpensive method of assessing haemostatis status when compared to complete coagulation profile. However, the extent or accuracy of thrombocytopenia being considered as a pointer to coagulation failure in preeclampsia is still not apparent.

The aim of the study was to determine platelet count which predicted coagulopathy in patients with severe preeclampsia and eclampsia.

\section{METHODS}

This study was a prospective cohort study which was conducted in Department of Obstetrics and Gynaecology in SVS Medical College between November 2019 and April 2020, with the approval of institutional ethical committee.

Informed consent form was obtained from all patients.

All patients were admitted with diagnosis of severe preeclampsia and eclampsia and admitted for stabilisation.

Exclusion criteria were patients with intrauterine foetal death, known coagulation disorders like haemophillias, immune thrombocytopenic purpura, inherited thrombocytopenia, Von Willebrand disease, abruptio placenta, acute or chronic liver disease like hepatitis, thromboembolic disorders, sickle cell disease. The patients who had antenatal care were considered to be booked and those not registered were considered to be unbooked. Preeclampsia is a pregnancy condition which is characterised by high blood pressure which usually begins after 20 weeks of pregnancy, sometimes fluid retention and proteinuria of $300 \mathrm{mg}$ or more in 24 hours urine sample also occurs. Eclampsia is also called as severe preeclampsia complication and is characterised by seizures during pregnancy or immediately after child birth. When the patient was admitted to labour ward either in coma or seizure, diagnosis of eclampsia was done. Seizure prophylaxis, blood pressure control, fluid replacement, electrolytes derangement correction, intrauterine resuscitation was the clinical management. Blood samples were collected from all patients for detecting bedtime clotting time, electrolytes, urea and creatinine, liver functions tests, full blood count, platelet count, prothrombin time, activated partial thromboplastin time and plasma fibrinogen level.

Thrombocytopenia is platelet count of less than 1 lakhs cells/ $\mu 1$, prolonged PT is more than $16 \mathrm{sec}$, prolonged APTT is more than $40 \mathrm{sec}$ and hypofibrinogenemia is less than $2 \mathrm{~g} / \mathrm{dl}$. Using Chi square test, univariate analysis was conducted. $P$ value of less than 0.05 was considered to be significant.

\section{RESULTS}

Out of 100 women patients, $70(70 \%)$ patients had severe preeclampsia and $30(30 \%)$ patients had eclampsia out of which 15 patients had thrombocytopenia. The incidence of thrombocytopenia among patients was $16.6 \%$. Biochemical coagulopathy was noted in $7 \%$. Table 1 shows that the maximum number of patients with thrombocytopenia was in the age range of 21-35 years. The parity was maximum i.e.; $60 \%$ in patients with thrombocytopenia in the parity range of 1-4. The gestational age in weeks was highest in $54 \%$ of patients with $\geq 38$ weeks.

Table 2 shows that patients with thrombocytopenia had fibrinogen $(\mathrm{g} / \mathrm{dl})$ was $2.14 \pm 0.58$ and highest $(67 \%)$ was between 2-4, APPTT in sec was $34.21 \pm 4.87$ and highest (73\%) was between $26-40$, PT in sec was $18.65 \pm 4.28$ and highest (53\%) was between 11-16.

Table 4 shows that patients with severe preeclampsia had platelet count of $185000 \pm 61289$ per $\mu 1$, PT was $13.52 \pm 1.48$ sec, APTT was 34.52 \pm 2.49 sec and fibrinogen was $3.16 \pm 0.22 \mathrm{~g} / \mathrm{dl}$. Patients with eclampsia (with thrombocytopenia) had platelet count of $79528 \pm 14897$ per $\mu 1$, PT was $19.25 \pm 5.28 \mathrm{sec}$, APTT was $37.08 \pm 5.33 \mathrm{sec}$ and fibrinogen was $2.67 \pm 0.53 \mathrm{~g} / \mathrm{dl}$.

Table 1: Distribution based on maternal demographic characteristics with respect to thrombocytopenia.

\begin{tabular}{|c|c|c|c|c|c|}
\hline \multirow{2}{*}{ Variables } & \multicolumn{2}{|c|}{ Thrombocytopenia $(n=15)$} & \multicolumn{2}{|c|}{ Normal $(n=85)$} & \multirow{2}{*}{$P$ value } \\
\hline & $\mathbf{N}$ & $\%$ & $\mathbf{N}$ & $\%$ & \\
\hline \multicolumn{5}{|c|}{ Age (years) } & \multirow{4}{*}{0.7113} \\
\hline$\leq 20$ & 2 & 13 & 5 & 6 & \\
\hline $21-35$ & 10 & 67 & 65 & 76 & \\
\hline$>35$ & 3 & 20 & 15 & 18 & \\
\hline \multicolumn{5}{|l|}{ Parity } & \multirow{4}{*}{0.124} \\
\hline 0 & 6 & 40 & 45 & 53 & \\
\hline $1-4$ & 9 & 60 & 32 & 37 & \\
\hline$>4$ & - & & 8 & 10 & \\
\hline
\end{tabular}

Continued. 


\begin{tabular}{|c|c|c|c|c|c|}
\hline \multirow{2}{*}{ Variables } & \multicolumn{2}{|c|}{ Thrombocytopenia $(n=15)$} & \multicolumn{2}{|c|}{ Normal $(\mathrm{n}=\mathbf{8 5})$} & \multirow{2}{*}{ P value } \\
\hline & $\mathbf{N}$ & $\%$ & $\mathbf{N}$ & $\%$ & \\
\hline \multicolumn{5}{|c|}{ Gestational age (weeks) } & \multirow{4}{*}{0.748} \\
\hline $21-33$ & 2 & 13 & 13 & 14 & \\
\hline $34-37$ & 5 & 33 & 36 & 43 & \\
\hline$\geq 38$ & 8 & 54 & 36 & 43 & \\
\hline
\end{tabular}

Table 2: Severity and frequency of abnormal plasma fibrinogen, APTT and PT in relation to thrombocytopenia.

\begin{tabular}{|c|c|c|c|c|c|}
\hline \multirow{2}{*}{ Variables } & \multicolumn{2}{|c|}{ Thrombocytopenia $(n=15)$} & \multicolumn{2}{|c|}{ Normal $(\mathrm{n}=\mathbf{8 5})$} & \multirow{2}{*}{ P value } \\
\hline & $\mathbf{N}$ & $\%$ & $\mathbf{N}$ & $\%$ & \\
\hline Fibrinogen (g/dl) & $2.14 \pm 0.58$ & & $3.54 \pm 0.14$ & & \\
\hline$<2$ & 5 & 33 & 0 & 0 & \multirow{3}{*}{0.001} \\
\hline $2-4$ & 10 & 67 & 85 & 100 & \\
\hline$>4$ & 0 & 0 & 0 & 0 & \\
\hline APTT (sec) & $34.21 \pm 4.87$ & & $32.19 \pm 2.49$ & & \\
\hline$<26$ & 0 & 0 & 0 & 0 & \multirow{3}{*}{0.001} \\
\hline $26-40$ & 11 & 73 & 85 & 100 & \\
\hline$>40$ & 4 & 27 & 0 & 0 & \\
\hline PT (sec) & $18.65 \pm 4.28$ & & $13.89 \pm 1.88$ & & \multirow{4}{*}{0.001} \\
\hline$<11$ & 0 & 0 & 0 & 0 & \\
\hline $11-16$ & 8 & 53 & 85 & 100 & \\
\hline$>16$ & 7 & 47 & 0 & 0 & \\
\hline
\end{tabular}

Note: PT: Prothrombin time, APTT: Activated partial thromboplastin time.

Table 3: Based on severity of thrombocytopenia, disorders of PT, APTT and plasma fibrinogen.

\begin{tabular}{|c|c|c|c|c|}
\hline \multirow{2}{*}{ Variables } & \multicolumn{3}{|c|}{ Severity of thrombocytopenia (cell/ $\mu \mathrm{l})$} & \multirow{2}{*}{$\begin{array}{l}P \\
\text { value }\end{array}$} \\
\hline & $<50000$ & $50000-80000(n=5) N(\%)$ & $81000-99999(n=10) N(\%)$ & \\
\hline Prolonged PT & - & $5(100 \%)$ & $3(30 \%)$ & 0.041 \\
\hline Prolonged APTT & - & $4(80 \%)$ & 0 & 0.012 \\
\hline Low fibrinogen & - & $5(100 \%)$ & 0 & 0.001 \\
\hline
\end{tabular}

Table 4: Eclampsia contribution to abnormalities in coagulation.

\begin{tabular}{|c|c|c|c|c|}
\hline \multirow{2}{*}{ Variables } & \multirow{2}{*}{$\begin{array}{l}\text { Severe preeclampsia } \\
\mathbf{n = 7 0}\end{array}$} & \multicolumn{2}{|l|}{ Eclampsia $(n=30)$} & \multirow{2}{*}{$\begin{array}{l}\mathbf{P} \\
\text { value }\end{array}$} \\
\hline & & With thrombocytopenia & Without thrombocytopenia & \\
\hline Platelet count (per $\mu \mathrm{l})$ & $185000 \pm 61289$ & $79528 \pm 14897$ & $205000 \pm 69524$ & 0.038 \\
\hline PT (sec) & $13.52 \pm 1.48$ & $19.25 \pm 5.28$ & $11.57 \pm 1.41$ & 0.001 \\
\hline APTT (sec) & $34.52 \pm 2.49$ & $37.08 \pm 5.33$ & $32.91 \pm 1.36$ & 0.036 \\
\hline Fibrinogen (g/dl) & $3.16 \pm 0.22$ & $2.67 \pm 0.53$ & $3.22 \pm 0.16$ & 0.001 \\
\hline
\end{tabular}

\section{DISCUSSION}

In preeclampsia and eclampsia, disseminated intravascular coagulopathy was one of the major cause of mortality. Effective prevention is a high index of clinical suspicion along with early confirmation of laboratory results always remains the primary approach. The incidence of thrombocytopenia among patients was $16.6 \%$. Biochemical coagulopathy was noted in $7 \%$. Most of patients were in advanced stages of gestation, younger than 35 years and they were unbooked. They had a higher coagulopathy risk than severe preeclampsia. Thrombocytopenia was worsened and the risk of hypofibrinogenemia, prolonged PT and APTT was enhanced. Ugwu et al and Ebeigbe et al conducted a study which was similar to the present study in contribution of unbooked patients which was higher in population of severe preeclamptics and eclamptics. ${ }^{6,7}$ For preeclampsia and eclampsia, nulliparity is a risk factor which is seen similarly in the present study and in Onuh et al study. ${ }^{8}$ The incidence of thrombocytopenia among patients in the present study was $16.6 \%$, which might probably reflect the coagulopathy level complicating preeclampsia and eclampsia. $7 \%$ biochemical coagulopathy rate found in the present study was found to be higher than $2 \%$ reported in Barker et al study, Sharma et al study and Pritchard et al, $6.7 \%$ in Awolola et al study..$^{9-12}$ In many studies, it was reported that thrombocytopenia is the most common haemostatic abnormality in patients which was similar to the present study. A lower rate than $28 \%$ to $50 \%$ was reported in many studies like Enaruna et al study and Rahim et al study. ${ }^{13,14}$ Few studies have shown similar results of $16.6 \%$ as the present study. ${ }^{11,15}$ This will suggest that our participants shall have a lower thrombocytopenia 
rate should be cut off be set at 150000 cells/ $\mu 1$. In patients with early onset of disease, the coagulopathy in preeclampsia appears to occur early with varying degrees. In the present study, coagulopathy risk was predicted by thrombocytopenia. Above 88,000 cells/ $\mu$ l platelet count, biochemical coagulopathy was present. At lower levels of thrombocytopenia, abnormal PT was common and APTT and fibrinogen abnormalities were evident.

The more severe the thrombocytopenia, likeliness of coagulopathy occurrence and poor prognosis is increased. The observation of only participants with low platelet count were observed to have biochemical coagulopathy has been found in other studies also. ${ }^{16,17}$ Minor abnormalities of PT, APTT and fibrinogen levels were reported frequently in patients with normal platelet count, moreover, this type of abnormality was found in patients with preeclampsia and eclampsia in Gerald et al study. ${ }^{18} \mathrm{In}$ Prieto et al study, no correlation was observed between platelet count levels and PT, APTT or fibrinogen. ${ }^{19}$ The results of Jambhulkar et al study were similar in that thrombocytopenia occurred more when eclampsia supervened. A prospective, case control, larger sample size study design will be able to compare mild preeclampsia and severe preeclampsia and the results obtained will be more valid and rugged.

\section{CONCLUSION}

Coagulopathy risk will be enhanced with worsening thrombocytopenia and eclampsia development. In the present study, 80000 cells/ $\mu$ l is the thrombocytopenia level which is considered to be critical in severe preeclampsia and eclampsia. This will help to reduce maternal and perinatal mortality and morbidity rates.

\section{Funding: No funding sources}

Conflict of interest: None declared

Ethical approval: The study was approved by the Institutional Ethics Committee

\section{REFERENCES}

1. Jahromi BN, Rafiee $\mathrm{SH}$, Coagulation factors in severe pre-eclampsia. IRCMJ. 2009;11:321-4.

2. Kay AP, Berg CJ, Atrash HK. Pregnancy-related mortality from preeclampsia and eclampsia. Obstet Gynecol. 2001;97(4):533-8.

3. Cunningham GF, Leveno JK, Bloom LS, Hauth CJ, Gilstrap L, Westrom DK. Hypertensive disorders in pregnancy. Willaims Obstetrics. 22nd ed. New York, NY: McGraw Hill; 2005: 761-808.

4. Perry KG, Martin JN. Abnormal hemostasis and coagulopathy in preeclampsia and eclampsia. Clin Obstet Gynecol. 1992;35(2):338-50.
5. Mammen EF. Disseminated intravascular coagulation (DIC). Clin Lab Sci. 2000;13(4):239-45.

6. Ugwu EO, Dim CC, Okonkwo CD, Nwankwo TO. Maternal and perinatal outcome of severe preeclampsia in Enugu, Nigeria after introduction of Magnesium sulfate. Niger $J$ Clin Pract. 2011;14(4):418-21.

7. Ebeigbe PN, Aziken ME. Early onset pregnancyinduced hypertension/eclampsia in Benin City, Nigeria. Niger J Clin Pract. 2010;13(4):388-93.

8. Onuh SO, Aisien AO. Maternal and fetal outcome in eclamptic patients in Benin City, Nigeria. J Obstet Gynaecol. 2004;24(7):765-8.

9. Barker P, Callander CC. Coagulation screening before epidural analgesia in pre-eclampsia. Anaesthesia. 1991;46(1):64-7.

10. Awolola OO, Enaruna NO. Determination of coagulopathy complicating severe preeclampsia and eclampsia with platelet count in a University Hospital, South-South, Nigeria. Trop J Obstet Gynaecol 2016;33:179-84.

11. Sharma SK, Philip J, Whitten CW, Padakandla UB, Landers DF. Assessment of changes in coagulation in parturients with preeclampsia using thromboelastography. Anesthesiology. 1999;90(2):385-90.

12. Pritchard JA, Cunningham FG, Mason RA. Coagulation changes in eclampsia: their frequency and pathogenesis. Am J Obstet Gynecol. 1976;124(8):855-64.

13. Enaruna NO, Osemwenkha AP. Clinical Correlates of Laboratory Abnormalities in Patients with Severe Pre-eclampsia at the University of Benin Teaching Hospital. J Med Biomed Res. 2013;12:81-90.

14. Rahim R, Nahar K, Khan IA. Platelet count in 100 cases of pregnancy induced hypertension. Mymensingh Med J. 2010;19(1):5-9.

15. Jambhulkar S, Shrikhande A, Shrivastava R, Deshmukh K. Coagulation Profile in Pregnancy Induced Hypertension. Indian $\mathrm{J}$ Hematol Blood Transfus. 2001;19:3-5.

16. Barron WM, Heckerling $\mathrm{P}$, Hibbard JU, Fisher S. Reducing unnecessary coagulation testing in hypertensive disorders of pregnancy. Obstet Gynecol. 1999;94(3):364-70.

17. Leduc L, Wheeler JM, Kirshon B, Mitchell P, Cotton DB. Coagulation profile in severe preeclampsia. Obstet Gynecol. 1992;79(1):14-8.

18. Fitz GMP, Floro C, Siegel J, Hernandez E. Laboratory findings in hypertensive disorders of pregnancy. J Natl Med Assoc. 1996;88(12):794-8.

19. Prieto JA, Mastrobattista JM, Blanco JD. Coagulation studies in patients with marked thrombocytopenia due to severe preeclampsia. Am J Perinatol. 1995;12(3):220-2.

Cite this article as: Jayashree V, Renukaa L.

Determination of coagulopathy complicating severe preeclampsia and eclampsia with platelet count. Int J Reprod Contracept Obstet Gynecol 2021;10:3755-8. 